\title{
AVALIAÇÃO ECONÔMICA DE ALTERNATIVAS DE INVESTIMENTO NO AGRONEGÓCIO DA UVA NO MEIO OESTE CATARINENSE ${ }^{1}$
}

\author{
CARLOS LEOMAR KREUZ², ALCEU SOUZA³, ÊNIO SCHUCK ${ }^{4}$, JOSÉ LUIZ PETRI ${ }^{5}$
}

\begin{abstract}
RESUMO - Este artigo analisa as expectativas de retorno associadas ao agronegócio uva para vinho e para suco, no Meio Oeste Catarinense. Detalham-se os investimentos, os custos de produção e a rentabilidade financeira inerentes a esta atividade, tendo-se por base a produção de uva para vinho e para suco, em três sistemas de sustentação: latada, manjedoura e espaldeira. A metodologia utilizada, baseada no fluxo de caixa descontado, consistiu na geração de indicadores de retorno e risco. Apesar da leve supremacia da produção de uva destinada para vinho, os indicadores calculados sinalizam para uma rentabilidade baixa tanto para o caso do vinho como para o suco.
\end{abstract}

Termos de indexação: rentabilidade; custos de produção; análise de viabilidade.

\section{ECONOMIC ANALYSIS OF INVESTMENT IN THE AGRIBUSINESS OF THE GRAPE IN THE HALF WEST SANTA CATARINA STATE}

\begin{abstract}
The present article aims at analyzing the production costs, profitability and risks involved in the grape agro-business addressed to wine and juice production in West of Santa Catarina state region. Investments, production costs, profitability and risks involved in this activity are described based on three support systems for wine grape and juice grape production: trellis, Y type trellis and Vertical trellis. The methodology, based on the discounted cash flow, generated return and risk indicators. These indicators show low profitability and medium risk concerning wine, and low profitability and risk concerning juice.
\end{abstract}

Index terms: yield of agribusiness; costs of grape production; viability analysis.

\section{INTRODUÇÃO}

A videira é uma atividade econômica difundida por todo o planeta, sendo sua origem bastante remota. Estudos arqueológicos revelaram fósseis de folhas de videira anteriores à última era glacial. A videira difundiu-se e adaptou-se pouco a pouco por diversas regiões do globo terrestre. Sua difusão ocorreu em duas principais direções: uma américo-asiática e outra euro-asiática, originando, respectivamente, as cultivares de uvas chamadas americanas e a outra chamada de européia ou Vitis vinifera (Epagri, 2004a).

A Itália e a França são os principais países produtores, cuja produção anual se aproxima de 10 mil toneladas cada. A produção brasileira gira em torno de $10 \%$ da dos principais países produtores (Office International de la Vigne et du Vin, 1999). A fraca participação do Brasil no cenário da produção mundial, aliada à abertura comercial iniciada nos anos 90, fazem do nosso País um dos dez maiores importadores de uvas, especialmente do Chile e da Argentina (Brito, 2003).

O Rio Grande do Sul, São Paulo, Paraná, Santa Catarina, Pernambuco, Bahia e Minas Gerais são os maiores produtores de uvas do Brasil. O Estado do Rio Grande do Sul, com quase 40 mil hectares plantados, destaca-se como sendo grande produtor de uvas no Brasil (Ibge, 2003).

A produção regional (meio oeste catarinense) é constituída principalmente de uvas de origem americana e híbrida. Na década de 70, com a criação em Santa Catarina do Projeto de Fruticultura de Clima Temperado - PROFIT, foi muito incentivado o plantio de castas européias. Porém, pelo despreparo da indústria local em processar essa matériaprima pela alta incidência de viroses (devido ao uso de material vegetativo não-selecionado), houve a eliminação dos parreirais de uvas viníferas. Com as uvas americanas e híbridas, também ocorreu um decréscimo da área plantada até meados dos anos noventa. Contribuíram para isso: a) o alto custo de implantação dos vinhedos; b) um mercado próximo da saturação; c) problemas de morte e declínio de plantas (Epagri, 2004a).

Contudo, nos últimos anos, em função dos bons preços prati- cados para uva e seus derivados, principalmente para as cultivares viníferas, está ocorrendo uma reversão das expectativas. Novos plantios estão ocorrendo na região, inclusive em áreas não-tradicionais para o cultivo da videira, como as regiões de elevada altitude (acima de 950 metros), no Planalto Serrano Catarinense, nos Campos de Água DoceSC, Caçador-SC, Campos Novos-SC e em Palmas-PR.

Apesar dos bons atrativos preços que têm sido observados no momento, a preocupação com a rentabilidade não pode desaparecer. Isto fica evidente em Protas \& Mello (2003) que relatam:

Um dos aspectos característicos e marcantes da vitivinicultura brasileira é a sua diversidade e complexidade. Na verdade, temos diversas vitiviniculturas no Brasil, cada uma com sua realidade climática, fundiária, tecnológica, humana e mercadológica. Entretanto, para qualquer uma delas, o cenário que se esboça neste início de século XXI, é de competição acirrada tanto no mercado externo quanto no interno, exigindo grande esforço de organização e política setorial (Protas \& Mello, 2003, p. 20).

O acirramento da competição prognosticado por Protas \& Mello (2003) conduz-nos, naturalmente, para o campo da rentabilidade do agronegócio da uva. Neste particular, a primeira definição diz respeito ao produto final que se deseja com o parreiral. Neste quesito, os profissionais da área agrícola, com base nas variáveis edafoclimáticas, afirmam que as regiões do Meio Oeste Catarinense e dos Campos de Palmas deverão caracterizar-se como sendo pólos de produção de suco de uva e/ou de vinho fino. A conclusão dos técnicos tem por base o fato de que, nas regiões mais altas do Sul do Brasil, face ao verão ser mais ameno, o ciclo vegetativo da uva é maior, o que acarreta em um teor maior de açúcar na uva. A conseqüência disto é que os principais produtos da industrialização da uva (suco e vinho) produzidos nesta região possuem características desejadas pelos consumidores. Ou seja, o suco é mais doce e o vinho não requer a adição de açúcar para que atinja o grau alcoólico desejado.

Porém os técnicos locais têm encontrado dificuldades em responder a perguntas relativas à rentabilidade dos parreirais destinados a

\footnotetext{
(Trabalho 103/2004). Recebido: 19/08/2004. Aceito para publicação: 07/07/2005.

${ }^{2}$ Dr.; Pesquisador da Epagri (Empresa de pesquisa Agropecuária e Extensão Rural de Santa Catarina) e Professor da UNICS (Centro Universitário Diocesano do Sudoeste do Paraná); Estação Experimental, CEP 89500-000, Caçador-SC; Fone 0..49-5630211; kreuz@epagri.rct-sc.br.

${ }^{3}$ Dr.; Professor da PUC-Pr (Universidade Católica do Paraná); telefone: (41) 271-1515 - alceusouza@bsi.net.br.

${ }^{4}$ M.Sc.; Pesquisador da Epagri (Empresa de pesquisa Agropecuária e Extensão Rural de Santa Catarina) e Professor da UNC (Universidade do Contestado); Fone: (049) 566-0054 - schuck@epagri.rct-sc.br.

${ }^{5}$ M.Sc.; Pesquisador da Epagri (Empresa de pesquisa Agropecuária e Extensão Rural de Santa Catarina) e Professor da UNC (Universidade do Contestado); Fone 0..49-5630211; petri@epagri.rct-sc.br.
} 
produzir uva para vinho e para suco. O questionamento tem origem no fato de que é no momento da implantação do parreiral que a decisão deve ser tomada. Isto porque as variedades de uva destinadas para suco não são as mesmas das destinadas para vinho. Além disso, o preço vigente para as mudas varia conforme estas se destinem para suco ou para vinho.

A segunda decisão que o fruticultor/investidor deve tomar, diz respeito ao sistema de sustentação (ou de condução) do parreiral. A necessidade de um sistema de sustentação é decorrência do fato de a videira ser uma planta trepadeira. Novamente a decisão deve ser tomada por ocasião da implantação do mesmo, uma vez que não existe a possibilidade de alteração do mesmo após o plantio (Miele \& Mandelli, 2003). Os três sistemas de sustentação mais conhecidos são os seguintes: latada, manjedoura e espaldeira. Para tornar mais complexa a decisão do investidor, os custos do sistema variam entre si, o mesmo ocorrendo com a produtividade.

O presente estudo analisa a viabilidade de investimentos nas diferentes combinações entre os sistemas de sustentação de uva e o produto final. Ou seja, busca-se comparar a rentabilidade financeira das seguintes combinações de produção de uva: latada para suco, latada para vinho, manjedoura para suco, manjedoura para vinho, espaldeira para suco e espaldeira para vinho.

\section{MATERIALEMÉTODOS}

Trata-se, segundo Silva \& Menezes (2003), de uma pesquisa aplicada quanto a sua natureza; quantitativa quanto à forma de abordagem do problema; descritiva e explicativa quanto ao seu objetivo, e de levantamento e bibliográfica quanto aos procedimentos técnicos de coleta de dados. É aplicada porque está direcionada à solução de problemas específicos; é quantitativa porque requer o uso de recursos matemáticos para solução e análise; é descritiva porque mapeia as atividades necessárias ao cultivo de 1 ha de uva; é explicativa porquanto objetiva esclarecer os fundamentos que caracterizam o agronegócio como sendo de baixa rentabilidade e de risco moderado para o vinho e rentabilidade e risco baixos para o caso do suco de uva; é de levantamento porque está sendo elaborada a partir de dados levantados junto a técnicos e produtores rurais da região e, por fim, é bibliográfica porque também se utiliza de material já publicado.

As informações necessárias para suportar este estudo foram obtidas de consultas diretas feitas a pesquisadores da área, extensionistas rurais, lideranças do setor e a produtores de uva no meio oeste

\begin{tabular}{|l|l|l|}
\hline INDICADOR & EXCEL $\mathbf{f}_{\mathbf{x}}$ & \multicolumn{1}{c|}{ INTERPRETAÇÃO } \\
\hline VPL & VPL & $\begin{array}{l}\text { Valor Presente Líquido : Corresponde à concentração de todos os valores de um fluxo de caixa, descontados } \\
\text { para a data zero (presente), usando-se como taxa de desconto a TMA (taxa de mínima atratividade). Representa, } \\
\text { em valores monetários de hoje, a diferença entre os recebimentos e os pagamentos de um projeto de } \\
\text { investimento. Se o VPL for positivo, significa que há expectativa de que sejam pagos todos os custos } \\
\text { operacionais do projeto; sejam recuperados o investimento inicial e também a parcela que seria auferida se esse } \\
\text { capital tivesse sido aplicado à TMA. O VPL expressa o ganho do pro jeto em relação à TMA para um horizonte } \\
\text { igual à duração do projeto. Embora não haja dúvida de que o VPL representa uma estimativa direta do aumento } \\
\text { da riqueza gerada por um empreendimento, esse indicador necessita ser trabalhado adicionalmente para } \\
\text { expressar essa riqueza em um horizonte de tempo mais convencional, ano por exemplo. }\end{array}$ \\
\hline IBC & VPL* & $\begin{array}{l}\text { Índice Benefício/Custo: Representa, para todo o horizonte de planejamento (N), as expectativas de ganho por } \\
\text { unidade capital investido no projeto em relação ao que se teria auferido se essa unidade de capital tivesse sido } \\
\text { aplicado à TMA. O IBC é uma estimativa da rentabilidade do projeto para todo o horizonte de planejamento. } \\
\text { A hipótese implícita no cálculo do IBC é que os recursos liberados ao longo da v ida útil do projeto são } \\
\text { reinvestidos à TMA. Possui em comum com o VPL, a característica indesejável de expressar a rentabilidade em } \\
\text { relação a todo o horizonte de planejamento do projeto (horizonte não-convencional). }\end{array}$ \\
\hline ROIA & $\begin{array}{l}\text { TAXA } \\
\text { mais convencional (ano) e, nesse caso, representa a melhor estimativa de rentabilidade anual do projeto além da } \\
\text { remuneração propiciada pela TMA. Pode ser interpretado como o análog o percentual do EVA. }\end{array}$ \\
\hline
\end{tabular}

* VP(Fluxo de Benefícios)/VP(Fluxo de Investimentos)

Fonte: Souza et al., 2002.

FIGURA 1 - Indicadores de retorno, função do Excel e interpretação

\begin{tabular}{|l|l|l|}
\hline INDICADOR & EXCEL $\mathbf{f}_{\mathbf{x}}$ & \multicolumn{1}{c|}{ INTERPRETAÇÃO } \\
\hline TIR & TIR & $\begin{array}{l}\text { Taxa Interna de Retorno : é a taxa que anula o Valor Presente Líquido de um fluxo de caixa. A TIR } \\
\text { deve ser interpretada como uma medida de risco da decisão. O risco de o projeto apresentar retorno } \\
\text { menor do que a aplicação financeira à TMA aumenta na medida em que a TMA se aproxi ma da TIR. } \\
\text { Assim, a TIR define um limite para a variação da TMA dentro do qual certo projeto oferece ganho } \\
\text { maior do a simples aplicação à TMA. A distância (ou proximidade) entre a TIR e a TMA pode ser } \\
\text { vista como uma medida de segurança (ou risco) do projeto. }\end{array}$ \\
\hline PAY -BACK & NPER & $\begin{array}{l}\text { Tempo para recuperação do Investimento: Representa o tempo necessário para que os benefícios do } \\
\text { projeto reponham o valor investido. Pode ser interpretado como uma medida de risco do projeto. } \\
\text { Projetos que apresentem pay -back menor en volvem um nível de risco mais baixo e vice -versa. Deve } \\
\text { ser utilizado com reservas para comparar projetos em diferentes ramos de atividade porquanto } \\
\text { desconsideram todos os eventos posteriores ao período de recuperação. Projetos, cujos pay } \\
\text { aproximem do final de sua vida econômica, via de regra, apresentam alto grau de risco. Exceção deve } \\
\text { ser feita à atividade de reflorestamento que, pela sua natureza, só apresenta resultados expressivos no } \\
\text { último ano. }\end{array}$ \\
\hline
\end{tabular}

FIGURA 2 - Indicadores de risco, função do Excel e interpretação 
catarinense.

As variáveis de análise foram: investimentos e custos de produção para as diferentes combinações de sistema de sustentação e produto final (latada para suco, latada para vinho, manjedoura para suco, manjedoura para vinho, espaldeira para suco e espaldeira para vinho), escala de produção e mercado.

Para os propósitos do cálculo de rentabilidade da uva, a remuneração dos títulos de baixo risco (CDB's RDB's, fundos mútuos, ...) foi utilizada como taxa de desconto (TMA) para o fluxo de caixa projetado.
Essa escolha seguiu a proposição de Souza \& Clemente (2004). Dessa forma, a rentabilidade obtida considerou como ganho apenas o excedente sobre aquilo que já se tem, isto é, o que será obtido além da aplicação do capital a TMA (10\% ao ano). Esse conceito é conhecido como o lucro residual ou ganho adicional.

O tratamento teórico dos indicadores utilizados, bem como as fórmulas de cálculo estão disponíveis em vários textos, como em Souza et al. (2002) e Souza \& Clemente (2004), e, por essa razão, não serão aqui apresentados. Considera-se útil, entretanto, apontar as

TABELA 1 - Coeficientes técnicos e custos para a implantação de 1ha de videira para vinho de acordo com o sistema de condução. Preços de maio de 2004.

\begin{tabular}{|c|c|c|c|c|c|c|c|c|}
\hline \multirow[t]{2}{*}{ Atividade } & \multirow[t]{2}{*}{ Unidade } & \multirow[t]{2}{*}{$\mathrm{R} \$ /$ Unid } & \multicolumn{2}{|c|}{ Latada } & \multicolumn{2}{|c|}{ Manjedoura } & \multicolumn{2}{|c|}{ Espaldeira } \\
\hline & & & Quant & Valor (R\$/ha) & Quant & Valor $(\mathrm{R} \$)$ & Quant & Valor $(\mathrm{R} \$)$ \\
\hline Total & & & & $30.826,70$ & & $32.554,98$ & & $29.220,63$ \\
\hline 1. Materiais & & & & $16.252,90$ & & $17.981,18$ & & $14.391,83$ \\
\hline Palanque externo concreto & Unidade & 40,00 & 118 & $4.720,00$ & & & & \\
\hline Rabicho de concreto & Unidade & 18,00 & 118 & $2.124,00$ & 68 & $1.224,00$ & & \\
\hline Palanque de madeira & Unidade & 35,00 & 4 & 140,00 & & & & \\
\hline Rabicho de madeira & Unidade & 33,00 & 4 & 132,00 & & & 70 & $2.310,00$ \\
\hline Pontalete de concreto & mil & 1500,00 & 1,2 & $1.800,00$ & & & & \\
\hline Arame galvanizado & $\mathrm{km}$ & 140,00 & 35 & $4.900,00$ & 24,5 & $3.430,00$ & 18,4 & $2.576,00$ \\
\hline Taquara & mil & 30,00 & 2,23 & 66,90 & 2,23 & 66,90 & 2,38 & 71,43 \\
\hline Palanque $3,8 \times 12 \times 12$ & Unidade & 16,15 & & & 68 & $1.098,20$ & & \\
\hline Palanque $3,6 \times 12 \times 12$ & Unidade & 11,52 & & & 544 & $6.266,88$ & 595 & $6.854,40$ \\
\hline Braços $1,55 \times 10 \times 10$ & Unidade & 2,50 & & & 1100 & $2.750,00$ & & \\
\hline Braços $1,55 \times 11 \times 13$ & Unidade & 3,00 & & & 136 & 408,00 & & \\
\hline Esticadores & Unidade & & & 870,00 & & 870,00 & & 540,00 \\
\hline Parafusos & Unidade & 0,60 & & & 612 & 367,20 & 900 & 540,00 \\
\hline Caixas de colheita & Unidade & 15,00 & 100 & $1.500,00$ & 100 & $1.500,00$ & 100 & $1.500,00$ \\
\hline 2. Insumos & & & & $10.196,30$ & & $10.196,30$ & & $10.721,30$ \\
\hline Mudas & Unidade & 3,50 & 2230 & $7.805,00$ & 2230 & $7.805,00$ & 2380 & $8.330,00$ \\
\hline Uréia & $\mathrm{sc}$ & 40,00 & 2 & 80,00 & 2 & 80,00 & 2 & 80,00 \\
\hline Superfosfato triplo & $\mathrm{sc}$ & 40,00 & 2 & 80,00 & 2 & 80,00 & 2 & 80,00 \\
\hline Fosfato natural & sc & 28,00 & 4 & 112,00 & 4 & 112,00 & 4 & 112,00 \\
\hline Cloreto de Potássio & $\mathrm{sc}$ & 40,00 & 4 & 160,00 & 4 & 160,00 & 4 & 160,00 \\
\hline Adubo orgânico & $\mathrm{m}^{3}$ & 36,00 & 20 & 720,00 & 20 & 720,00 & 20 & 720,00 \\
\hline Bórax & $\mathrm{kg}$ & 1,80 & 40 & 72,00 & 40 & 72,00 & 40 & 72,00 \\
\hline Dithane & $\mathrm{kg}$ & 23,00 & 2 & 46,00 & 2 & 46,00 & 2 & 46,00 \\
\hline Sulfato de cobre & $\mathrm{kg}$ & 2,10 & 5 & 10,50 & 5 & 10,50 & 5 & 10,50 \\
\hline Cal & $\mathrm{kg}$ & 0,18 & 10 & 1,80 & 10 & 1,80 & 10 & 1,80 \\
\hline Decis & 1 & 48,00 & 0,5 & 24,00 & 0,5 & 24,00 & 0,5 & 24,00 \\
\hline Formicida & $\mathrm{kg}$ & 17,00 & 5 & 85,00 & 5 & 85,00 & 5 & 85,00 \\
\hline Calcário & $\mathrm{t}$ & 40,00 & 25 & $1.000,00$ & 25 & $1.000,00$ & 25 & $1.000,00$ \\
\hline 3. Preparo do solo & & & & $2.292,50$ & & $2.292,50$ & & $2.292,50$ \\
\hline Limpeza da área & $\mathrm{d} / \mathrm{h}$ & 15,00 & 10 & 150,00 & 10 & 150,00 & 10 & 150,00 \\
\hline Limpeza da área & $\mathrm{h} / \mathrm{tr}$ & 25,00 & 20 & 500,00 & 20 & 500,00 & 20 & 500,00 \\
\hline Limpeza da área - esteira & $\mathrm{h} / \mathrm{tr}$ & 90,00 & 5 & 450,00 & 5 & 450,00 & 5 & 450,00 \\
\hline Subsolagem & $\mathrm{h} / \mathrm{tr}$ & 90,00 & 8 & 720,00 & 8 & 720,00 & 8 & 720,00 \\
\hline Aração & $\mathrm{h} / \mathrm{tr}$ & 25,00 & 10 & 250,00 & 10 & 250,00 & 10 & 250,00 \\
\hline Distribuição calcáreo & $\mathrm{h} / \mathrm{tr}$ & 25,00 & 4 & 100,00 & 4 & 100,00 & 4 & 100,00 \\
\hline Distribuição calcáreo & $\mathrm{d} / \mathrm{h}$ & 15,00 & 1,5 & 22,50 & 1,5 & 22,50 & 1,5 & 22,50 \\
\hline Adubação & $\mathrm{h} / \mathrm{tr}$ & 25,00 & 4 & 100,00 & 4 & 100,00 & 4 & 100,00 \\
\hline 4. Instalação do parreiral & & & & $2.085,00$ & & $2.085,00$ & & $1.815,00$ \\
\hline Demarcação da área & $\mathrm{d} / \mathrm{h}$ & 15,00 & 6 & 90,00 & 6 & 90,00 & 6 & 90,00 \\
\hline Plantio & $\mathrm{d} / \mathrm{h}$ & 15,00 & 15 & 225,00 & 15 & 225,00 & 15 & 225,00 \\
\hline Tutoramento & $\mathrm{d} / \mathrm{h}$ & 15,00 & 6 & 90,00 & 6 & 90,00 & 6 & 90,00 \\
\hline Combate a formigas & $\mathrm{d} / \mathrm{h}$ & 15,00 & 2 & 30,00 & 2 & 30,00 & 2 & 30,00 \\
\hline Tratamentos fitossanitários & $\mathrm{d} / \mathrm{h}$ & 15,00 & 5 & 75,00 & 5 & 75,00 & 5 & 75,00 \\
\hline Eliminar brotações & $\mathrm{d} / \mathrm{h}$ & 15,00 & 5 & 75,00 & 5 & 75,00 & 5 & 75,00 \\
\hline Capinas & $\mathrm{d} / \mathrm{h}$ & 15,00 & 20 & 300,00 & 20 & 300,00 & 20 & 300,00 \\
\hline Sistema de sustentação & $\mathrm{d} / \mathrm{h}$ & 15,00 & 70 & $1.050,00$ & 70 & $1.050,00$ & 55 & 825,00 \\
\hline Poda de inverno e amarração & $\mathrm{d} / \mathrm{h}$ & 15,00 & 10 & 150,00 & 10 & 150,00 & 7 & 105,00 \\
\hline
\end{tabular}

Fonte: dados primários. 
TABELA 2 - Coeficientes técnicos e custos para a condução de 1ha de videira para vinho, no segundo ciclo vegetativo, de acordo com o sistema de condução. Preços de maio de 2004.

\begin{tabular}{|c|c|c|c|c|c|c|c|c|}
\hline \multirow[t]{2}{*}{ Atividade } & \multirow[t]{2}{*}{ Unidade } & \multirow[t]{2}{*}{$\mathrm{R} \$ /$ Unid } & \multicolumn{2}{|c|}{ Latada } & \multicolumn{2}{|c|}{ Manjedoura } & \multicolumn{2}{|c|}{ Espaldeira } \\
\hline & & & Quant & Valor (R\$/ha) & Quant & Valor (R\$) & Quant & Valor $(\mathrm{R} \$)$ \\
\hline \multicolumn{9}{|l|}{ 1. Insumos } \\
\hline Dithane & $\mathrm{kg}$ & 23,00 & 8 & 184,00 & 8 & 184,00 & 8 & 184,00 \\
\hline Sulfato de cobre & $\mathrm{kg}$ & 1,25 & 14 & 17,50 & 14 & 17,50 & 14 & 17,50 \\
\hline Cal hidratada & $\mathrm{kg}$ & 0,18 & 28 & 5,04 & 28 & 5,04 & 28 & 5,04 \\
\hline \multicolumn{9}{|l|}{ 2. Atividades } \\
\hline Adubação & $\mathrm{dh}$ & 15,00 & 2 & 30,00 & 2 & 30,00 & 2 & 30,00 \\
\hline Roçada & $\mathrm{h} / \mathrm{tr}$ & 25,00 & 9 & 225,00 & 9 & 225,00 & 9 & 225,00 \\
\hline Replanta & $\mathrm{dh}$ & 15,00 & 2 & 30,00 & 2 & 30,00 & 2 & 30,00 \\
\hline Tutoramento & $\mathrm{dh}$ & 15,00 & 1 & 15,00 & 1 & 15,00 & 1 & 15,00 \\
\hline Poda de inverno e amarração & $\mathrm{dh}$ & 15,00 & 7 & 105,00 & 5,5 & 82,50 & 4,5 & 67,50 \\
\hline Colheita & $\mathrm{dh}$ & 15,00 & 15,6 & 234,00 & 7,5 & 112,50 & 6 & 90,00 \\
\hline Transporte da produção & $\mathrm{h} / \mathrm{tr}$ & 25,00 & 1 & 25,00 & 1 & 25,00 & 1 & 25,00 \\
\hline
\end{tabular}

Fonte: dados primários

funções financeiras do EXCEL que foram utilizadas. Além disso, são apresentadas, embora de forma resumida, as interpretações adequadas desses indicadores. A Figura 1 apresenta os indicadores de retorno que compõem a metodologia proposta, as funções do EXCEL e a forma adequada de interpretação. A Figura 2 refere-se aos indicadores de risco.

\section{RESULTADOS}

Os coeficientes para a implantação referem-se a áreas onde não há necessidade de destoca ou queimada. A Tabela 1 apresenta os coeficientes técnicos e os resultados monetários associados à implantação (e condução no primeiro ciclo vegetativo) de 1 hectare de videira, nos três sistemas de condução com o propósito de produção de uva para vinho. O sistema manjedoura considerado foi baseado em uma estrutura de madeira.

No que se refere aos coeficientes técnicos para a implantação e a condução do primeiro ciclo vegetativo de 1 ha de videira com o objetivo da produção de suco de uva, a principal alteração diz respeito ao custo da muda. Enquanto o custo da muda de videira destinada para a produção de vinho gira em torno de $\mathrm{R} \$ 3,50$ (Três Reais e cinqüenta centavos), o custo da muda para a produção de suco é bem inferior: R\$ 1,00 (um Real). Este aspecto torna o custo de implantação da videira para suco inferior ao do vinho. A principal razão de o preço da muda variar conforme o objetivo da produção diz respeito às cultivares recomendadas (Epagri, 2004b).

Quanto à condução do segundo ciclo vegetativo, do terceiro e do parreiral adulto (Tabelas $2 ; 3 ; 4 ; 5 ; 6$ e 7), as diferenças de custos se expressam tanto entre os sistemas quanto ao produto objeto do parreiral. Entre os sistemas, as diferenças se expressam principalmente no uso da mão-de-obra para a poda e para a colheita, sendo o sistema em espaldeira o menos exigente em mão-de-obra, uma vez que as atividades manuais são mais facilitadas. Já no que diz respeito ao objetivo final (suco ou vinho), as diferenças se expressam, também, no uso de insumos (o uso de fungicidas é em torno de $50 \%$ inferior para o caso da produção de uva para suco), no uso de máquinas para os tratamentos fitossanitários (o qual se reduz face ao menor uso de fungicidas na produção de suco) e na necessidade de mão-de-obra para a colheita (a qual, dada a maior produção a ser colhida, é superior no caso do suco).

As informações contidas nas Tabelas 1 a 7 permitiram a cons- trução dos fluxos de caixa (Tabela 8) das seis opções para a exploração de 1 hectare de videira. As receitas foram obtidas supondo-se preços de $\mathrm{R} \$ 0,40 / \mathrm{kg}$ de uva para suco e $\mathrm{R} \$ 1,40 / \mathrm{kg}$ de uva para vinho. As produtividades consideradas supõem um teto de 30t/ha para o caso da uva destinada para a produção de suco nos sistemas latada e manjedoura. No caso da produção de uva para vinho, a produtividade limita-se a 20t/ ha no sistema latada e $18 \mathrm{t}$ /ha no manjedoura. O sistema espaldeira é o menos produtivo, quer o objetivo seja uva para suco (15t/ha), quer seja para vinho $(12 \mathrm{t} / \mathrm{ha})$.

A Tabela 9 apresenta os resultados dos indicadores de retorno (VPL e ROIA) e de risco (TIR e Pay-back) para a exploração de 1 ha de uva. Ressalta-se o diferencial de rentabilidade $(16 \%, 14,17 \%$ e $11,96 \%$ ao ano) do vinho em relação ao suco de uva $(6,83 \%$ e $6,53 \%$ ao ano). A opção suco em espaldeira não se mostrou competitiva.

\section{DISCUSSÃO}

Comparando-se os resultados encontrados (Tabela 9) com os de outros estudos na região (Souza et al., 2002; Kreuz, 2003; Kreuz et al., 2003a; Kreuz et al., 2003b), a análise dos indicadores de viabilidade do cultivo de 1 hectare de uva indica ser de média para baixa a rentabilidade do agronegócio uva. Tendo-se por base o ROIA anual, a melhor opção (uva para vinho no sistema latada) possibilita um ganho de $16 \%$ ao ano acima dos $10 \%$ que seria auferido pela decisão de não empreender.

Apesar do melhor resultado apresentado pelo sistema latada, a diferença para o sistema manjedoura não chega a ser expressiva $(16 \%$ e 14,17\%). Por outro lado, observações empíricas feitas na região indicam que o uso do sistema latada não tem sido a decisão preferencial adotada pelos investidores. Os investidores em uva para vinho têm dado preferência para o sistema em manjedoura. Esta decisão tem sido embasada principalmente na possibilidade do uso de cobertura plástica no empreendimento. Esta prática, apesar de implicar um investimento ainda maior, reduz os riscos climáticos a que a atividade está sujeita.

Alguns investidores em uva para vinho optam, também, pelo sistema espaldeira. Duas têm sido as justificativas para tal. Uma delas está associada às facilidades para a execução das atividades manuais. A outra é a possibilidade do controle da produtividade. Argumenta-se que o controle da produtividade possibilita uma qualidade superior da uva (maior Grau Brix). 
TABELA 3 - Coeficientes técnicos e custos para a condução de 1ha de videira para suco, no segundo ciclo vegetativo, de acordo com o sistema de condução. Preços de maio de 2004.

\begin{tabular}{|c|c|c|c|c|c|c|c|c|}
\hline \multirow[t]{2}{*}{ Atividade } & \multirow[t]{2}{*}{ Unidade } & \multirow[t]{2}{*}{ R\$/Unid } & \multicolumn{2}{|c|}{ Latada } & \multicolumn{2}{|c|}{ Manjedoura } & \multicolumn{2}{|c|}{ Espaldeira } \\
\hline & & & Quant & Valor $(\mathrm{R} \$ / \mathrm{ha})$ & Quant & Valor $(\mathrm{R} \$)$ & Quant & Valor)(R\$ \\
\hline SEGUNDO CICLO & & & & $1.449,79$ & & $\mathbf{1 . 3 7 9 , 7 7}$ & & $1.264,77$ \\
\hline \multicolumn{9}{|l|}{ 1. Insumos } \\
\hline Uréia & $\mathrm{sc}$ & 40,00 & 3 & 120,00 & 3 & 120,00 & 3 & 120,00 \\
\hline Dithane & $\mathrm{kg}$ & 23,00 & 4 & 92,00 & 4 & 92,00 & 4 & 92,00 \\
\hline Sulfato de cobre & $\mathrm{kg}$ & 1,25 & 7 & 8,75 & 7 & 8,75 & 7 & 8,75 \\
\hline Cal hidratada & $\mathrm{kg}$ & 0,18 & 28 & 5,04 & 14 & 2,52 & 14 & 2,52 \\
\hline Decis & 1 & 48,00 & 0,5 & 24,00 & 0,5 & 24,00 & 0,5 & 24,00 \\
\hline Formicida & $\mathrm{kg}$ & 17,00 & 5 & 85,00 & 5 & 85,00 & 5 & 85,00 \\
\hline \multicolumn{9}{|l|}{ 2. Atividades } \\
\hline Adubação & $\mathrm{dh}$ & 15,00 & 2 & 30,00 & 2 & 30,00 & 2 & 30,00 \\
\hline Roçada & $\mathrm{h} / \mathrm{tr}$ & 25,00 & 9 & 225,00 & 9 & 225,00 & 9 & 225,00 \\
\hline Replanta & $\mathrm{dh}$ & 15,00 & 2 & 30,00 & 2 & 30,00 & 2 & 30,00 \\
\hline Tutoramento & $\mathrm{dh}$ & 15,00 & 1 & 15,00 & 1 & 15,00 & 1 & 15,00 \\
\hline Combate formigas & $\mathrm{dh}$ & 15,00 & 4 & 60,00 & 4 & 60,00 & 4 & 60,00 \\
\hline Tratamentos fitossanitários & $\mathrm{h} / \mathrm{tr}$ & 25,00 & 10 & 250,00 & 10 & 250,00 & 10 & 250,00 \\
\hline Eliminação de brotação & $\mathrm{d} / \mathrm{h}$ & 15,00 & 2 & 30,00 & 2 & 30,00 & 2 & 30,00 \\
\hline Capina & $\mathrm{d} / \mathrm{h}$ & 15,00 & 10 & 150,00 & 10 & 150,00 & 10 & 150,00 \\
\hline Poda de inverno e amarração & $\mathrm{dh}$ & 15,00 & 7 & 105,00 & 5,5 & 82,50 & 4,5 & 67,50 \\
\hline Colheita & $\mathrm{dh}$ & 15,00 & 13 & 195,00 & 10 & 150,00 & 5 & 75,00 \\
\hline Transporte da produção & $\mathrm{h} / \mathrm{tr}$ & 25,00 & 1 & 25,00 & 1 & 25,00 & 1 & 25,00 \\
\hline
\end{tabular}

Fonte: dados primários

TABELA 4 - Coeficientes técnicos e custos para a condução de 1ha de videira para vinho, no terceiro ciclo vegetativo, de acordo com o sistema de condução. Preços de maio de 2004.

\begin{tabular}{|c|c|c|c|c|c|c|c|c|}
\hline \multirow[t]{2}{*}{ Atividade } & \multirow[t]{2}{*}{ Unidade } & \multirow[t]{2}{*}{$\mathrm{R} \$ /$ Unid } & \multicolumn{2}{|c|}{ Latada } & \multicolumn{2}{|c|}{ Manjedoura } & \multicolumn{2}{|c|}{ Espaldeira } \\
\hline & & & Quant & Valor (R\$/ha) & Quant & Valor $(\mathrm{R} \$)$ & Quant & Valor $(\mathrm{R} \$)$ \\
\hline TERCEIRO CICLO & & & & $2.044,98$ & & $1.935,61$ & & $1.796,48$ \\
\hline \multicolumn{9}{|l|}{ 1. Insumos } \\
\hline Uréia & $\mathrm{sc}$ & 40,00 & 2 & 80,00 & 2 & 80,00 & 2 & 80,00 \\
\hline Dithane & $\mathrm{kg}$ & 23,00 & 10 & 230,00 & 10 & 230,00 & 10 & 230,00 \\
\hline Sulfato de cobre & $\mathrm{kg}$ & 1,25 & 36 & 45,00 & 36 & 45,00 & 36 & 45,00 \\
\hline Cal hidratada & $\mathrm{kg}$ & 0,18 & 36 & 6,48 & 36 & 6,48 & 36 & 6,48 \\
\hline Decis & 1 & 48,00 & 0,5 & 24,00 & 0,5 & 24,00 & 0,5 & 24,00 \\
\hline Formicida & $\mathrm{kg}$ & 17,00 & 1 & 17,00 & 1 & 17,00 & 1 & 17,00 \\
\hline \multicolumn{9}{|l|}{ 2. Atividades } \\
\hline Adubação & $\mathrm{d} / \mathrm{h}$ & 15,00 & 2 & 30,00 & 2 & 30,00 & 2 & 30,00 \\
\hline Roçada & $\mathrm{h} / \mathrm{tr}$ & 25,00 & 9 & 225,00 & 9 & 225,00 & 9 & 225,00 \\
\hline Combate formigas & $\mathrm{dh}$ & 15,00 & 2 & 30,00 & 2 & 30,00 & 2 & 30,00 \\
\hline Tratamentos fitossanitários & $\mathrm{h} / \mathrm{tr}$ & 25,00 & 25 & 625,00 & 25 & 625,00 & 25 & 625,00 \\
\hline Eliminação de brotação & $\mathrm{d} / \mathrm{h}$ & 15,00 & 2 & 30,00 & 2 & 30,00 & 2 & 30,00 \\
\hline Capina & $\mathrm{d} / \mathrm{h}$ & 15,00 & 10 & 150,00 & 10 & 150,00 & 10 & 150,00 \\
\hline Poda de inverno e amarração & $\mathrm{d} / \mathrm{h}$ & 15,00 & 14 & 210,00 & 11 & 165,00 & 9 & 135,00 \\
\hline Colheita & $\mathrm{d} / \mathrm{h}$ & 15,00 & 19,5 & 292,50 & 16,9 & 253,13 & 9,6 & 144,00 \\
\hline Transporte da produção & $\mathrm{h} / \mathrm{tr}$ & 25,00 & 2 & 50,00 & 1 & 25,00 & 1 & 25,00 \\
\hline
\end{tabular}

Fonte: dados primários

TABELA 5 - Coeficientes técnicos e custos para a condução de 1ha de videira para suco, no terceiro ciclo vegetativo, de acordo com o sistema de condução. Preços de maio de 2004.

\begin{tabular}{|c|c|c|c|c|c|c|c|c|}
\hline \multirow[t]{2}{*}{ Atividade } & \multirow[t]{2}{*}{ Unidade } & \multirow[t]{2}{*}{$\mathrm{R} \$ /$ Unid } & \multicolumn{2}{|c|}{ Latada } & \multicolumn{2}{|c|}{ Manjedoura } & \multicolumn{2}{|c|}{ Espaldeira } \\
\hline & & & Quant & Valor (R\$/ha) & Quant & Valor (R\$) & Quant & $\overline{\text { Valor }(\mathrm{R} \$)}$ \\
\hline TERCEIRO CICLO & & & & $1.786,74$ & & $1.791,74$ & & $1.319,24$ \\
\hline \multicolumn{9}{|l|}{ 1. Insumos } \\
\hline Uréia & $\mathrm{sc}$ & 40,00 & 2 & 80,00 & 2 & 80,00 & 2 & 80,00 \\
\hline Dithane & $\mathrm{kg}$ & 23,00 & 5 & 115,00 & 5 & 115,00 & 5 & 115,00 \\
\hline Sulfato de cobre & $\mathrm{kg}$ & 1,25 & 18 & 22,50 & 18 & 22,50 & 18 & 22,50 \\
\hline Cal hidratada & $\mathrm{kg}$ & 0,18 & 18 & 3,24 & 18 & 3,24 & 18 & 3,24 \\
\hline Decis & 1 & 48,00 & 0,5 & 24,00 & 0,5 & 24,00 & 0,5 & 24,00 \\
\hline Formicida & $\mathrm{kg}$ & 17,00 & 1 & 17,00 & 1 & 17,00 & 1 & 17,00 \\
\hline \multicolumn{9}{|l|}{ 2. Atividades } \\
\hline Adubação & $\mathrm{d} / \mathrm{h}$ & 15,00 & 2 & 30,00 & 2 & 30,00 & 2 & 30,00 \\
\hline Roçada & $\mathrm{h} / \mathrm{tr}$ & 25,00 & 9 & 225,00 & 9 & 225,00 & 9 & 225,00 \\
\hline Combate formigas & dh & 15,00 & 2 & 30,00 & 2 & 30,00 & 2 & 30,00 \\
\hline Tratamentos fitossanitários & $\mathrm{h} / \mathrm{tr}$ & 25,00 & 12,5 & 312,50 & 12,5 & 312,50 & 12,5 & 312,50 \\
\hline Eliminação de brotação & $\mathrm{d} / \mathrm{h}$ & 15,00 & 2 & 30,00 & 2 & 30,00 & 2 & 30,00 \\
\hline Capina & $\mathrm{d} / \mathrm{h}$ & 15,00 & 10 & 150,00 & 10 & 150,00 & 10 & 150,00 \\
\hline Poda de inverno e amarração & $\mathrm{d} / \mathrm{h}$ & 15,00 & 14 & 210,00 & 11 & 165,00 & 9 & 135,00 \\
\hline Colheita & $\mathrm{d} / \mathrm{h}$ & 15,00 & 32,5 & 487,50 & 37,5 & 562,50 & 8 & 120,00 \\
\hline Transporte da produção & $\mathrm{h} / \mathrm{tr}$ & 25,00 & 2 & 50,00 & 1 & 25,00 & 1 & 25,00 \\
\hline
\end{tabular}


TABELA 6 - Coeficientes técnicos e custos para a condução de 1ha de videira para vinho, em idade adulta, de acordo com o sistema de condução. Preços de maio de 2004.

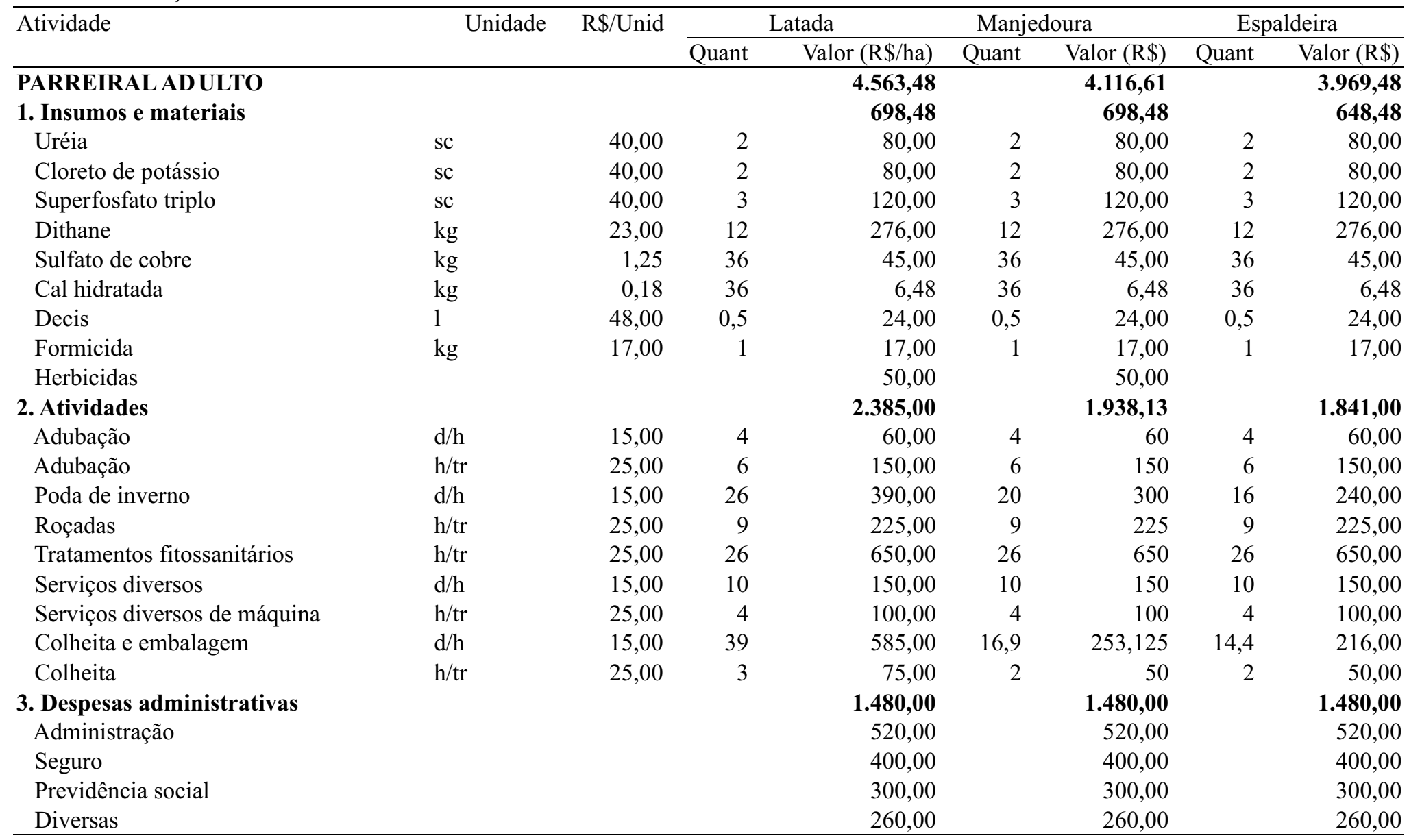

Fonte: dados primários

TABELA 7 - Coeficientes técnicos e custos para a condução de 1ha de videira para suco, em idade adulta, de acordo com o sistema de condução. Preços de maio de 2004.

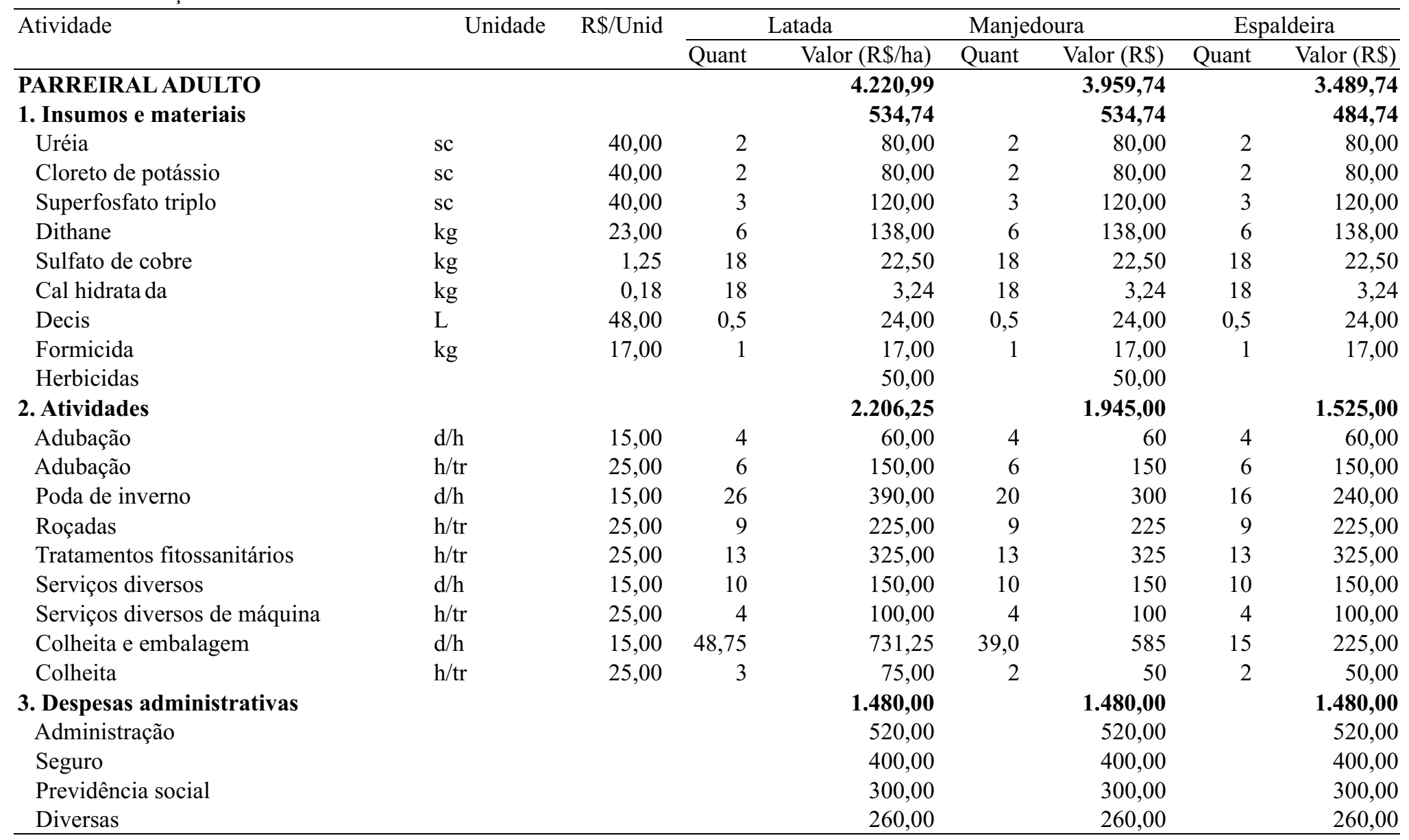

Fonte: dados primários 
TABELA 8 - Produtividade, desembolsos e fluxo de caixa para a exploração de 1 ha do agronegócio uva $\left({ }^{1}\right)$. Preços de maio de 2004.

\begin{tabular}{|c|c|c|c|c|c|c|c|c|c|c|c|c|c|c|c|c|c|c|}
\hline \multirow[t]{2}{*}{ Ano } & \multicolumn{6}{|c|}{ Produtividade (t/ha) } & \multicolumn{6}{|c|}{ Desembolsos (R \$ 1.000/ha } & \multicolumn{6}{|c|}{ Fluxo de Caixa (R\$ 1.000/ha) } \\
\hline & $\mathrm{LS}^{1}$ & LV & MS & MV & ES & EV & LS & LV & MS & MV & ES & EV & LS & $\mathrm{LV}$ & MS & MV & ES & $\mathrm{EV}$ \\
\hline 1 & 0 & 0 & 0 & 0 & 0 & 0 & 25,70 & 30,83 & 27,43 & 32,55 & 23,75 & 29,22 & $-25,70$ & $-30,83$ & $-27,43$ & $-32,55$ & 23,75 & $-29,22$ \\
\hline 2 & 8 & 8 & 8 & 5 & 5 & 8 & 1,45 & 1,84 & 1,38 & 1,70 & 1,26 & 1,63 & 1,75 & 10,16 & 1,82 & 5,80 & 0,74 & 10,37 \\
\hline 3 & 20 & 10 & 20 & 8 & 8 & 10 & 1,79 & 2,04 & 1,79 & 1,94 & 1,32 & 1,80 & 6,21 & 12,96 & 6,21 & 10,06 & 1,88 & 13,20 \\
\hline 4 & 25 & 15 & 25 & 13 & 10 & 12 & 4,22 & 4,56 & 3,96 & 4,12 & 3,49 & 3,97 & 5,78 & 17,94 & 6,04 & 15,38 & 0,51 & 14,03 \\
\hline 5 & 30 & 20 & 30 & 18 & 15 & 12 & 4,22 & 4,56 & 3,96 & 4,12 & 3,49 & 3,97 & 7,78 & 25,44 & & 22,88 & 51 & 14,03 \\
\hline 6 & 30 & 20 & 30 & 18 & 15 & 12 & 4,22 & 4,56 & 3,96 & 4,12 & 3,49 & 3,97 & 7,78 & 25,44 & 8,04 & 22,88 & 2,51 & 14,03 \\
\hline 7 & 30 & 20 & 30 & 18 & 15 & 12 & 4,22 & 4,56 & 3,96 & 4,12 & 3,49 & 3 , & 7,78 & 25,44 & 8,04 & 22,88 & 2,51 & 14,03 \\
\hline 8 & 30 & 20 & 30 & 18 & 15 & 12 & 4,22 & & 3,96 & 4,12 & 49 & & 7,78 & 44 & & 22,88 &, 51 & 14,03 \\
\hline 9 & 30 & 20 & 30 & 18 & 15 & 12 & 4,22 & 4,56 & 3,96 & 4,12 & 3,49 & 3,97 & 7,78 & 25,44 & 8,04 & 22,88 & 2,51 & 14,03 \\
\hline 10 & 30 & 20 & 30 & 18 & 15 & 12 & 4,22 & 4,56 & 3,96 & 4,12 & 3,49 & 3 & 7,78 & 25 , & 8 , & 22,88 & 2,51 & 14,03 \\
\hline 11 & 30 & 20 & 30 & 18 & 15 & 12 & 4,22 & & 3,96 & 4,12 & 49 & & 7,78 & 25 & & 22,88 &, 51 & 14,03 \\
\hline 12 & 30 & 20 & 30 & 18 & 15 & 12 & 4,22 & 4,56 & 3,96 & 4,12 & 3,49 & 3 & 7,78 & 25,44 & 8, & 22,88 & 2,51 & 14,03 \\
\hline 13 & 30 & 20 & 30 & 18 & 15 & 12 & 4,22 & 4,56 & 3,96 & 4,12 & 3,49 & 3 & 7,78 & 25,44 & 8,04 & 22,88 & 2,51 & 14,03 \\
\hline 14 & 30 & 20 & 30 & 18 & 15 & 12 & 4,22 & & 3 & 4,12 & 3 & & 7,78 & 25 & 4 & 22,88 &, 51 & 14,03 \\
\hline 15 & 30 & 20 & 30 & 18 & 15 & 12 & 4,22 & 4, & 3,96 & 4,12 & 3,49 & 3 & 7,78 & 25,44 & 8,04 & 22,88 & 2,51 & 14,03 \\
\hline 16 & 30 & 20 & 30 & 18 & 15 & 12 & 4,22 & 4 & 3,96 & 4,12 & 3,49 & & 7,78 & 25,44 & 8,04 & 22,88 & 2,51 & 14,03 \\
\hline 17 & 30 & 20 & 30 & 18 & 15 & 12 & 4,22 & 4,56 & 3,96 & 4,12 & 3,49 & 3 , & 7,78 & 25,44 & 8,04 & 22,88 & 2,51 & 14,03 \\
\hline 1 & 30 & 20 & 30 & 18 & 15 & 12 & 4,22 & 4,56 & 3,96 & 4,12 & 3,49 & 3 & 7,78 & 25,44 & 8,04 & 22,88 & 2,51 & 14,03 \\
\hline 1 & 30 & 20 & 30 & 18 & 15 & 12 & 20 & & & 4,12 & 3 , & & 7,78 & 25,44 & 8 , & 22,88 & 2,51 & 14,03 \\
\hline 20 & 30 & 20 & 30 & 18 & 15 & 12 & 4,22 & 4,56 & 3,96 & 4,12 & 3,49 & 3,97 & 7,78 & 25,44 & 8,04 & 22,88 & 2,51 & 14,03 \\
\hline
\end{tabular}

$\left({ }^{1}\right)$ LS $\rightarrow$ Latada Suco; LV $\rightarrow$ Latada Vinho; MS $\rightarrow$ Manjedoura Suco; MV $\rightarrow$ Manjedoura Vinho; ES $\rightarrow$ Espaldeira Suco; EV $\rightarrow$ Espaldeira Vinho.

TABELA 9 - Indicadores de viabilidade da exploração de 1 ha do agronegócio uva. Preços de maio de 2004.

\begin{tabular}{|c|c|c|c|c|c|c|}
\hline \multirow[t]{2}{*}{ Indicador } & \multicolumn{2}{|c|}{ Latada } & \multicolumn{2}{|c|}{ Manjedoura } & \multicolumn{2}{|c|}{ Espaldeira } \\
\hline & Suco & Vinho & Suco & Vinho & Suco & Vinho \\
\hline VP Investimentos & 25.698 & 30.827 & 27.426 & 32.555 & 23.747 & 29.221 \\
\hline VP Benefícios & 56.793 & 182.937 & 58.585 & 159.662 & 14.362 & 113.350 \\
\hline VPL & 31.096 & 152.110 & 31.159 & 127.107 & $(6.385)$ & 84.130 \\
\hline ROIA (por ano) & $6,83 \%$ & $16,00 \%$ & $6,53 \%$ & $14,17 \%$ & & $11,96 \%$ \\
\hline ROIA (por mês) & $0,55 \%$ & $1,24 \%$ & $0,53 \%$ & $1,11 \%$ & $0,00 \%$ & $0,95 \%$ \\
\hline TIR & $23,36 \%$ & $52,65 \%$ & $22,62 \%$ & $42,83 \%$ & & $43,56 \%$ \\
\hline Pay-back (em anos) & 7 & 3 & 7 & 4 & & 3 \\
\hline
\end{tabular}

Desta forma, novos estudos devem ser conduzidos buscando quantificar os efeitos que a cobertura plástica traz ao resultado do empreendimento. O mesmo pode ser dito do controle da produtividade no sistema espaldeira. O que pode ser afirmado é que, com as informações disponíveis até o momento, o sistema latada é o que possibilita o melhor resultado financeiro.

Outros investidores, ainda, têm direcionado seus parreirais para a produção de suco. Apesar do resultado financeiro inferior, esta pode ser uma solução razoável para os vitivinicultores iniciantes, principalmente dada a menor exigência fitossanitária. Contudo, o sistema de sustentação deve, necessariamente, ser o latada ou o manjedoura, pois o sistema de sustentação em espaldeira é financeiramente inviável. A principal razão da não-viabilização do sistema em espaldeira para a produção de suco se deve à produtividade atingível ficar em $50 \%$ da dos dois outros sistemas (Tabela 8).

De modo geral, a superioridade financeira da uva destinada para a produção de vinho em relação à uva destinada à produção de suco se deve ao mercado. Apesar de as produtividades, independentemente do sistema de sustentação, serem maiores na produção de uva para suco (Tabela 8), o melhor preço de venda da uva para vinho acaba possibilitando maiores receitas ao produtor. Desta forma, enquanto persistir a atual diferença nos preços entre a uva destinada para vinho e a destinada para suco, o produtor deve, preferencialmente, optar pela produção de uva para vinho.

Os indicadores de resultado calculados (Tabela 9) possibilitam uma série de considerações de ordem financeira. Em função de ter apresentado maior rentabilidade (Tabela 9), tomar-se-á a opção latada para vinho como base para a interpretação dos indicadores. a) Valor Presente Líquido (VPL)

Ao optar pelo investimento no agronegócio uva com objetivo de produção (latada) de vinho, as expectativas são que o produtor recupere os investimentos efetuados; recupere também o que teria auferido se esse capital tivesse sido aplicado no mercado financeiro a $10 \%$ ao ano, e ainda lhe sobrem, em valores monetários de maio de 2004, a importância de R \$ 152.110 (cento e cinqüenta e dois mil e cento e dez reais). É importante destacar que esse é um retorno para 1 ha de terra e para um horizonte de 19 anos, isto é, a terra ficará imobilizada por 19 anos e, só depois desse período, poder-se-á pensar em outro uso alternativo para a mesma.

\section{b) Retorno adicional decorrente do investimento ( $\left.\mathrm{ROIA}_{\text {anual }}\right)$}

$\mathrm{O}_{\mathrm{ROIA}}$ anual representa as expectativas quanto à rentabilidade anual desse agronegócio. O ROIA está estimado em 16\% ao ano (ou $1,24 \%$ ao mês) além do que se teria obtido se o capital tivesse sido aplicado no mercado financeiro a $10 \%$ ao ano. Este resultado evidencia que a rentabilidade desse investimento não é expressiva e pode pensarse que esse patamar de rentabilidade funcione como estímulo à busca de novos posicionamentos competitivos e/ou novos arranjos produtivos.

\section{c) Taxa interna de retorno (TIR)}

A TIR define um limite para a variação da TMA. Enquanto a TMA (estimada em 10\% ao ano) permanecer inferior à TIR (52,65\% ao ano), as expectativas são que haja mais ganho em se investir no projeto do que deixar o dinheiro aplicado recebendo a TMA. O risco está sendo interpretado como a possibilidade de se ganhar mais deixando o capital 
aplicado no mercado a $10 \%$ ao ano do que investi-lo no cultivo de 1 hectare do agronegócio uva. O resultado sinaliza para um risco financeiro baixo para esse agronegócio.

\section{d) Pay-back}

Para o empreendimento em análise, a expectativa é a recuperação do investimento já no $3^{\circ}$ ano. O valor encontrado para o agronegócio uva (latada para vinho) sinaliza para um risco muito baixo de não-recuperação do capital investido.

\section{CONCLUSÕES}

1. O risco financeiro do agronegócio uva é baixo, isto é, a chance de se ganhar mais dinheiro no mercado do que na atividade de empreender fica descartada pela distância entre a TIR e a TMA.

2. A uva destinada para a produção de vinho, apesar de a produtividade ser menor, representa uma opção mais rentável ao produtor quando comparada à uva destinada à produção de suco. Isso decorre principalmente em função dos maiores preços de mercado das uvas destinadas à produção de vinho.

3. A comparação entre si da rentabilidade dos diferentes sistemas de sustentação mostra o latada como o de maior rentabilidade, independentemente de o uso da uva ser o vinho ou o suco. Já o sistema espaldeira mostra-se inviável, particularmente para a produção de suco.

\section{REFERÊNCIAS}

BRITO, F. A. Uva. In: INSTITUTO DE PLANEJAMENTO E ECONOMIA AGRÍCOLA DE SANTA CATARINA. Síntese da agricultura de Santa Catarina-2002-2003. Florianópolis: ICEPA, 2003.

EPAGRI. Normas técnicas para o cultivo da videira em Santa Catarina. Florianópolis: Epagri, 2004a. (Normas Técnicas).

EPAGRI. Avaliação de cultivares para o Estado de Santa Catarina 20042005. Florianópolis: Epagri, 2004b. (Boletim Técnico).
IBGE. Levantamento Sistemático da Produção agrícola 2003. Disponível em: <http://www.sidra.ibge.gov.br>. Acesso em: 23 jun. 2003.

KREUZ, C. L. Análise da competitividade de atividades agrícolas na região de Caçador, Santa Catarina. Florianópolis: Epagri, 2003. (Documento, 209).

KREUZ, C. L. et al. Análise de clusters e estratégias competitivas para agronegócios: o caso da produção de Maçã no Sul do Brasil. In: ASAMBLEA ANUAL CLADEA, 38., 2003, Lima. Anais... Lima: Cladea, 2003a CD-ROM.

KREUZ, C. L. et al. Indicadores de viabilidade e estratégias competitivas: o caso dos produtores de alho na região de Curitibanos - SC. In: CONGRESO DEL INSTITUTO INTERNACIONAL DECOSTOS, 8., 2003, Punta del Este. Anais... Punta del Este: IIC, 2003b. CDROM.

MIELE, A.; MANDELLI, F. Sistemas de condução para a videira para os Campos de Palmas. In: SEMINÁRIO ESTADUAL DE FRUTICULTURA, 3., 2003, Palmas, Pr. Anais... Palmas, Pr: Facipal, 2003.

OFFICE INTERNATIONAL DE LA VIGNE ET DU VIN. Bulletin de I'O.I.V. Paris: Office International de la Vigne et du Vin, 1999 (supplement).

PROTAS, J. F. S.; MELLO, L. M. R. A vitivinicultura brasileira: o panorama mercadológico e suas perspectivas. In: Seminário Estadual de Fruticultura, III, 2003, Palmas, Pr. Anais... Palmas, Pr: Facipal, 2003.

SILVA, E. L.; MENEZES, E. M. Metodologia da pesquisa e elaboração de dissertação. Disponível em: $<$ http://www.eps.ufsc.br>. Acesso em: 18 jul. 2003.

SOUZA, A.; CLEMENTE, A. Decisões financeiras e análise de investimentos. São Paulo: Atlas, 2004.

SOUZA, A. et al. A. Metodologia para análise de viabilidade do cultivo de Pinus taeda: o caso da região dos Campos de Palmas. Revista de Negócios, Blumenau, v. 7, n. 4, p. 51-62, 2002. 